\title{
Investigating the Problems that Students Encounter in Common First Year at Majmaah University in Using the Simple Present Tense Correctly
}

\author{
Dr.Lana Hussain Ahmed Shehata \\ Assistant Professor - English Department - Majmaah University - Common First Year- KSA.
}

\begin{abstract}
This study aims to shed light on the problems that face common first year (CFY) students at Majmaah University - KSA in using the present simple tense, and to find out whether they receive proper techniques to improve their usage of the present simple and to highlight some of effective methods which help them to use the present simple tense correctly. This study use the methods of discusses descriptive analytical approach to data collection by Test. The populations of this study are students of common first year at Majmaah University - KSA. The study took place for academic year. The samples of this study are 60 students from Majmaah University first common year. In this study, only one tool used for data collection, designed test contains of 20 questions divided into four parts to explore the problems of using the present simple tense correctly among (CFY) students. The data were analyzed using statistical software packages for social sciences (SPSS) program. The results of the study concluded that the students have general background about the present simple tense but they do not have sufficient ability to form the verbs correctly and they lack awareness of the adverbs beside their weakness of forming negative and interrogative. With the reference to the results of the study, the researcher recommended that The present simple tense should paid more attention, should be taught in the beginning at secondary school effectively, the students should do many classroom activities and exercises about the simple present tense, also the teachers should use motivations methods to enhance the students' level in the present simple tense. The researcher suggests the following further areas for other researchers: 1) Investigate the problems which encounter secondary school students in using inflectional morphemes (s, es, ies ) of the present simple tense.2) Comparative studies could be conducted to find similarities and dissimilarities between the present simple tense and other tenses. 3) Investigating the problems that encounter secondary school students in using the present simple tense when they write a descriptive paragraph.

Keywords: importance - difficulties - effective methods- simple present tense- adverbs - common first year (CFY)
\end{abstract}

DOI: $10.7176 / \mathrm{JEP} / 11-9-18$

Publication date:March $31^{\text {st }} 2020$

\subsection{Statement of the Study}

The students of common first year at Majmaah university level don't know well the use and functions of the present simple tense; they lack the ability of using the present simple tense in communication and they commit errors when they try to answer the examinations' questions. They do not realize the rules of the verbs formation .As a result, they write sentences with incorrect grammar. Also this study identify the grammatical errors, classified the errors of using simple present tense in the students' descriptive text to determine the frequency of errors.

\subsection{Objectives of the Study}

This study aims:

1. To investigate the problems which face (CFY) students in using the present simple tense correctly.

2. To find out whether students receive proper techniques to promote optimum using of the present simple tense correctly or not.

3. To highlight some of the effective methods which help the students to use the present simple tense correctly.

\subsection{Research Questions}

1. To what extents do (CFY) students are able to use the present simple tense correctly?

2. To what extent do (CFY) students unable to use the present simple tense correctly?

3. To what extend do students find difficulties in forming negative and interrogative sentences in the present simple tense?

\subsection{The Research Hypotheses}

1. CFY students have a sufficient ability to use the present simple tense correctly.

2. CFY students have not a sufficient ability to use the present simple tense correctly.

3. CFY students find difficulties in forming negative and interrogative sentences in the present simple tense. 


\subsection{The Significance of the Study Problem}

It is well known that English is considered as a global language. It plays an important role in our life. The importance of this study is that it investigates one of the most significant parts of grammar. Students at Majmaah University (CFY) level are unable to master this very important part of language. The purpose of this study is to find what the learners know and do not know, and to uncover the problems which faced by students.

\section{Literature Review}

\subsection{Definitions of the Present Simple Tense}

Tense is a systematic structure to describe different forms of verbs that showed the time of action. Meanwhile, simple present tense is formed by using the simple form of the verb that is the form which was listed in the dictionary or it was called infinitive without 'to'. When the third person singular subject is present, an -es or $-\mathrm{s}$ ending is added Cook and Suter, (1983:49). stated that the present simple tense expresses an action or a state of being in the present.

The simple present tense is one of several forms of present tense in English. It is used to describe habits, unchanging situations, general truths, and fixed arrangements. The simple present tense is simple to form. Just use the base form of the verb: (I take, you take, we take, and they take) the 3rd person singular takes an -s at the end. (He takes, she takes). The present simple tense is a regular habits or daily routine use the simple present to express the idea that an action is repeated or usual, the action can be habit, a hoppy, a daily event or something that often happens. Those sentences which denote a habit, a universal fact or experience are in the simple present tense. The simple present is a verb tense with two main uses. We use the simple present tense when an action is happening right now, or when it happens regularly (or unceasingly, which is why it's sometimes called present indefinite).

https:/www.ef.com/wwen/english-resources/english-grammar/simple-present-tense/

The simple present (also called present simple or present indefinite) is a verb tense which is used to show repetition, habit or generalization. Less commonly, the simple present can be used to talk about scheduled actions in the near future and, in some cases, actions happening now. The simple present tense indicates that an action is present. Generally, it is used for factual or habitual actions - things which occur in the present but are not necessarily occurring now. The simple present tense is also used to denote events that are scheduled to happen either by nature or by people. The present simple tense uses to describe habits, facts, states, and regular actions. It is the most common tense in English.

https://www.englishpage.com/verbpage/simplepresent.html

Norma gold man and etal - (1983) state that the present tense is first used for the present time. The present tense is the tense for description, definition and statements of general truth. Patricia Wilox (1996) states that The present tense extends from the past time through the present and into the future. The present tense is called the present habitual, is used for repeated habitual action. Simple Present Tense is used for the incidents those have been occurring at the moment or are happening routinely over a period of time. The present simple is actually used to describe an action that is immediate to the speaker. For that you are more likely to use the present progressive (e.g., I am typing right now). Instead, the present simple is primarily used to describe recurring, timeless, and habitual actions. That's why the present simple is often accompanied by references to time (every day, tomorrow, sometimes, etc.).

\subsection{The Importance of Learning the Present Simple Tense}

The present simple tense is the most important tense for secondary students of English to learn. To be able to communicate intelligibly they need to master at least the basic rules. If they don't they will struggle with many other grammar rules. Therefore it is crucial that they learn this tense. On the other hand Effective communication skills of English language are necessary for the people of all professions. The concept of English verb tenses is very important in establishing effective communication. Hence, if you want to maintain both ways of communication better, that is, speaking and writing.Brown (1980, P. 264) states "in learning a language we must know the grammar rules for forming correct sentence". Thornbury (2002) states that grammar is "sentences making machine". Muneera and Shameem (2013) affirm that knowledge of Grammar particularly tenses, is the most required and awkward part for non-native speakers to master.

\subsection{The Usages of the Present Simple Tense}

Frank, (1972:66) stated that the simple present tense could be used:

(a) To express a habitual action, with adverbs like usually, always, or often.

Example: They often play football together.

(b) To state a general truth

Example: The earth revolves around the sun.

(C) To express future action, especially with verbs of movement or travel such as:

'Come', 'leave', 'stay', or 'arrive'. 
Example: I arrive in Khartoum on Saturday.

(d) In commentaries on games and plays

Example: He takes the shuttlecock and sends it high above the net.

(e) In exclamations, announcements or demonstrations.

Example: Our club gives its annual dinner next week.

Moreover, Azzar (1981:20) stated that the simple present tense is used to express events or situations that exist always, usually, habitually; they exist now, have existed in the past, and probably will exist in the future. For example: It snows in Alaska.

The simple present tense is also used to express non-action states or condition.

The present simple tense also could be used to express:

(a) Mental states: know, understand, believe, think, agree, etc.

Example: She knows you very well.

I think you are right.

(b) Emotional states: like, love, hate, appreciate, etc.

Example: Tarig loves football match very much.

(c) Sense perception: see, hear, taste, smell, feel, etc.

Example: Do you hear me now?

I feel cold today.

(d) Possession: have, own, belong, and possess.

Example: Ahmed has a new car.

This house belongs to Mr. Ali.

(e) Other existing states: costs, weight, contain, appear, etc.

Example: This dictionary costs. 70.000, Sudanese Pounds

This package contains books and Laptop.

Wren and Martin (1995-68) add other use of simple present tense such as the following;

(a) It is used to introduce questions

John Keats - says 'a thing of beauty

Is Joy forever?

(b) it is used instead of the simple future tense, in clause of time and conditions ;

- I shall wait till you finish your lunch.

- If it rains, we shall get wet.

\subsection{The Problems face Students in Using the Present Simple Tense}

Mahmoud (2005,P.124 ) states that "errors indicate that EFL students depend on inter lingual and inter lingual interference strategies to facilitate learning " such strategies and lead to him, help in the case of perceived linguistic similarities and lead to problems in the case of differences (ibid). Learning English tenses and their uses have an important role in the whole process of communication. Nowadays, learning and using English tenses is the most difficult problem. In learning and using a foreign language, one of the most inhibiting factors is the fear of making mistakes or errors. As I'm a teacher at Sudan secondary schools I notice that the most students commit errors when they answering questions in the present simple, the most of their errors occur when they try to form the verbs. On the other hand they are not familiar to write descriptive texts using the present simple tense. The use of simple present tense often confuses students, especially when simple present tense is used in descriptive writing. When the descriptive writer makes an error in simple present tense, it means that the writer is not careful enough in making their text vivid and detailed.

\section{5-Difficulties and Errors in Forming Correct Verbs}

The present simple tense is typically one of the first verb tenses that new English students learn. It is used to describe action that takes place on a regular basis The students usually face difficulty in English grammar that is in arranging words into correct utterances or sentences. It means that grammar is one of the most important parts of English to communicate with others. When we communicate, both in written and spoken ways with other people, we should not only have a good vocabulary but also correct grammar. Therefore, without grammar, it is hard for people to understand what we say or write because grammar makes a string of words or utterances meaningful. Lightbown and Spada, (2006) stated that Error in language learning and knowledge of grammar has become one of the most important aspects that indicate development of second language (L2) learners' Inter language (ILG) system. Corder (1981: 260) has argued that errors are considered to be the features of the learner's utterances which are in one way or another different from those of the native speakers. He further states that the learners of a target language are not aware of their errors and thus are unable to correct these errors themselves. The process by which these errors are encountered, computed and analyzed is called Errors Analysis. When teaching the simple present tense, there are several considerations teachers have to take into account. First, 
some irregular verbs may confuse students. For instance, the verb 'have' and 'be' have different forms in the simple present (has, am, are,...) A second concern is related to the dropping of the 's' of the third person singular which many students seem to forget. Another difficulty is the spelling of the forms that take the ' $s$ ' of the third person singular. Sometimes, only ' $s$ ' is added (close - closes) while in some forms 'es' is added (watch - watches.) Finally, interrogative and negative forms which necessitate the auxiliary 'do' may represent another challenge for beginner students. Many kinds of errors arise for students learning English because they do not master English well. They commit errors by not using the rules of the components and elements of the second language Ramelan Brown, (1992). Said, "Second language learning is a process that is clearly not unlike first language learning in its trial and errors nature." Gass and Slinker, (1994) stated that the students learning English cannot avoid errors in learning a second language. Frank (1972:66): states "Simple present tense is used to express a habitual action with adverbs such as usually, always, or often." The use of simple present tense often confuses students, especially when simple present tense is used in descriptive writing. When the descriptive writer makes an error in simple present tense, it means that the writer is not careful enough in making their text vivid and detailed.

In order to analyse the errors in the use of simple present tense, it is necessary to make distinction between errors and mistakes. According to Ellis, errors reflect gaps in a learners' knowledge; they occur because the learner does not know what is correct. Ellis, $(1997 ; 17)$ states that. While, mistakes reflect occasional lapses in performance; they occur because, in particular instance, the learner is unable to perform what he or she knows .Mistake is a fault which is made by the learner and he or she can make correction. Meanwhile, error is a fault which is made by the learner, and he or she is unable to make correction. Brown (1980: 163) stated that 'a mistake refers to a performance error that is either a random guess or a slip in that it is a failure to utilize a known system correctly. Lightbown and Spada, (2006) stated "Meanwhile, error is a noticeable deviation from the adult grammar of a native speaker, reflecting the inter language competence of the learner'. Error in language learning and knowledge of grammar has become one of the most important aspects that indicate development of second language (L2) learners' Inter language (ILG) system". Corder (1981: 260) has argued that errors are considered to be the features of the learner's utterances which are in one way or another different from those of the native speakers. He further states that the learners of a target language are not aware of their errors and thus are unable to correct these errors themselves.

The process by which these errors are encountered, computed and analysed is called Errors Analysis. It also helps the second language researchers to recognize the students' learning problems as well as the factors triggering it. Corder, (1967), cited in Ellis, (1994) state that the teachers, on the other hand, can provide their students with appropriate feedback and can use this information to prepare appropriate teaching materials and to design more effective lesson plans. As for the students/language learners themselves, the analysis is inevitable to language learning improvement. That is to say, analysing these errors which are considered to be systematic in nature is insightful information for second language teachers, learners, researchers and the classroom teaching practice as well. Norris and Ortega (2003, p. 717) have argued that error analysis is "used to elicit, observe and record the language (and language related behaviour of second language learners) and to enable the resulting evidence in light of explanatory theories of the language acquisition process". Most of the studies on error analysis focus on errors in grammar and structure. The difference between first language (L1) and second language (L2) grammar is assumed to be the major cause of second language learners' errors. The purpose of this study is to examine the acquisition of English tense specifically the present simple tense as it is considered to be problematic for Sudanese secondary school students learning English as a foreign language. This difficulty can be attributed to the differences between the first and the second language(s) (i.e. Arabic and English respectively).

The main objective of this study is to analyze students' errors in present simple tense and identify the sources of errors as taken from the grammaticality judgment task and the elicited written production task by Sudanese Secondary school students as well as to provide some pedagogical implications for the English as a foreign language classroom teaching practice as well for second language teachers and researcher.

\subsection{The Problems face students in using the adverbs in the present simple tense}

Many (CFY) students have not sufficient proficiency in using the adverbs of the present simple tense; many of them do not have ability to distinguish between the adverbs of the present simple tense and the adverbs of other tenses. Also they find difficulties to put adverbs in the proper situation when they asked to arrange some words in order to form sentences.

\subsection{Anticipated Problems}

Here are the most common challenges for students when using the present simple as following:

Confusing with the present continuous for actions occurring at the moment of speaking.

Use of "s" in the third person.

Auxiliary verb usage in the question and negative form, but not in the positive form.

Placement of adverbs of frequency. 


\subsection{Strategies for Practicing the Present Simple}

After students have completed the lesson they will be able to complete most basic linguistic functions (giving personal information, identifying and basic description skills, talking about basic daily tasks, and how often those tasks are done). While there is obviously a lot more learning to be done, students can then feel confident that they have a strong base on which to build in the future. With this lesson, you can help students begin speaking in longer phrases by having them prepare a talk on their daily activities that they can then read or recite to their fellow classmates and which can then be used as the basis for questions.

\subsection{The Effective Methods of Teaching the Present Simple Tense}

When teaching the Present Simple the ultimate goal is to make sure your students understand that it's used to describe routines, habits, daily activities, and general truths. Also it is important to contrast between the Present Simple and the Present Progressive. This series of steps will guide you towards teaching the Present Simple and covers function, conjugation, and form. Introduce an action, Introduce Present Simple - First person singular, Introduce Present Simple - Second person singular, Introduce Present Simple - Third person singular, Do the same for the plural persons, Introduce Present Simple - Negative, Introduce Present Simple - Interrogative, Expand and practice present simple exercises, and teach the present simple tense by introducing texts. Grammar Game is one of some choices which can be used to Deepen the students" understanding in all kinds of English Structures.

\subsection{Previous Studies}

The first previous study which related to my research is by Sheryl Holt, (1997). She stated, in her article on grammar errors that sentence - level (es) errors are fairly consistent regardless of the leaner's first language. Such thing means that many errors are due to the complex structure of English rather than to language interference or students learning ability. Then she stated what she called "the most common errors in English as the second language writing" based on her twenty - years' experience of teaching and university of Minnesota. The errors are English verb tense, model auxiliaries, verb followed by 'ing' of infinitive forms, conditional forms, transitive / intransitive verbs and passive voice; idioms, phrases or word choice, singular - plural agreement; reduce forms; propositions; articles and sentence structure. Holt state that "tenses for instance are of great difficulty to speakers of some languages and it is very difficult to over - come such difficulty" she recommended the (es) I writing " teachers neither ignore nor over correct grammar errors.

The second previous study which related to my research is by Elkhateeb, (2003); He analyzed in Gaza city, the study was confined to the common errors of three tenses (present - past - future). The study was applied on random sample which consists of 200 males / females students from general secondary school certificate. The data were collected from writing compositions. These topics were designed to test the ability of students to express about his / her ideas in the (present - past - future simple tense). The results showed that the errors were classified into eight types; 1) tense shift 2) verb substitution 3) verb incorrectly formed 4) copula omission 5) wrong tense 6) copula redundancy 7) subject verb agreement 8) verb omission. The result also showed that the highest percentage of errors has been found in ' s ' $15-20 \%$ of present simple tense where the lowest present ages of errors were in ' V O' area $9.30 \%$ of all errors. The results also showed that there were significant differences between male / female performance in all previous area.

The third previous study which related to my research is by Abdul Raheem, M. (1999); the most common errors among the students of English at the colleges of education in Gazza the test revealed that "tenses and articles" were most problematic grammatical area faced by the subjects; the results showed that the success percentage was 63. The overall mean scores was 45.7 out of 100 with standard deviation of 11,17 . Forty three students got the degree of "pass ", eleven students got the degree "good" and only one got the degree "very good". The researcher recommended that instructors should concentrate on the semantics of the tenses and articles as they should start their instruction of these syntactic areas from the similarities between the systems of English and Arabic language. Finally the researcher classified the students' errors according to the degree of their seriousness and frequency of their occurrence; wrong word order, wrong use of tenses, misuse of tenses, of prepositions, of articles, omission of indirect object pronouns, the indefinite ' it as subject, wrong use of certain words, orthography and miscellaneous.

\subsection{Summary}

After considering and viewing the literature, it has been noticed that students have difficulties and errors in many areas in English language and one of these areas is tenses, i.e. Tenses would be the major source of difficulty and hence errors and such studies agree on his point. In comparison with the studies on the identification, classification, and description of tenses errors, the majority of these studies point at and focused on several types of errors while very few investigated tenses' errors. These studies differed on the order they assigned to tenses on the hierarchy of difficulty they present. 


\section{Methodology of the Study}

In this paper, the researcher uses the descriptive analytical method to conduct the research. The researcher designed a test to collect data, in using the present simple tense. The test consists of; choosing the correct verbs, forming the verbs in brackets correctly, and reforming affirmative sentences into negative and interrogative sentences of the present simple tense. The researcher select 60 students from common first year - Majmaah University -KSA, the test consist of four parts with 20 questions. The students' answers are analysed to explore the problems of using the present simple tense correctly.

\section{Data Analysis:}

1- Part One

Table (4.1) The frequency distribution's analysis for item one.

\begin{tabular}{|c|c|c|}
\hline Answer & Frequency & Percent \\
\hline True & 29 & $48.3 \%$ \\
\hline False & 31 & $51.7 \%$ \\
\hline Total & 60 & $100 \%$ \\
\hline
\end{tabular}

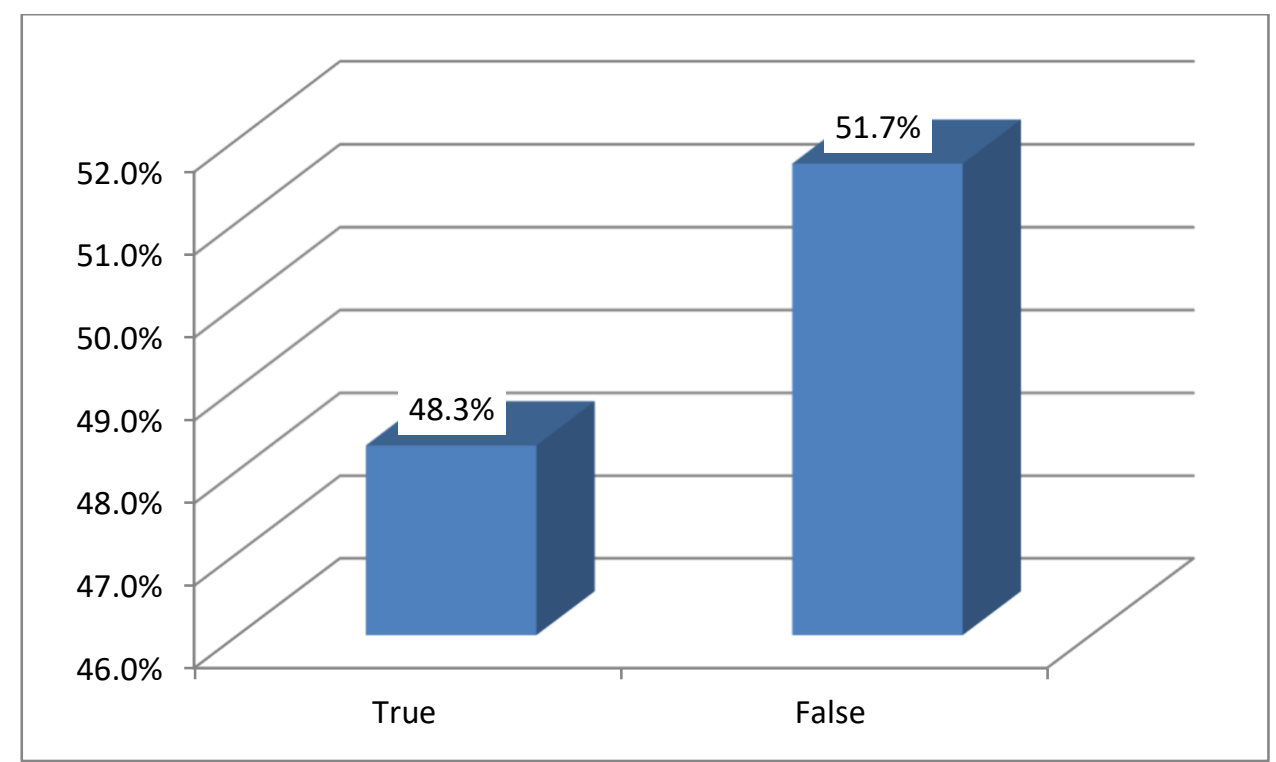

Figure (4.1) The frequency distribution's analysis for item one.

From table (1) and figure (1) we note that the answer of most of the individuals study is (False) by frequency (31) with percent $(51.7 \%)$ while the answer is (True) by frequency (29) with percent $(48.3 \%)$. respectively are high ,so the highest percentage is going to positive direction of the statements and most answers of the study sample are agreeable. Therefore this hypothesis is successfully achieved.

Table (4.2) The frequency distribution's analysis for item two.

\begin{tabular}{|c|c|c|}
\hline Answer & Frequency & percent \\
\hline True & 30 & $50 \%$ \\
\hline False & 30 & $50 \%$ \\
\hline Total & 60 & $100 \%$ \\
\hline
\end{tabular}




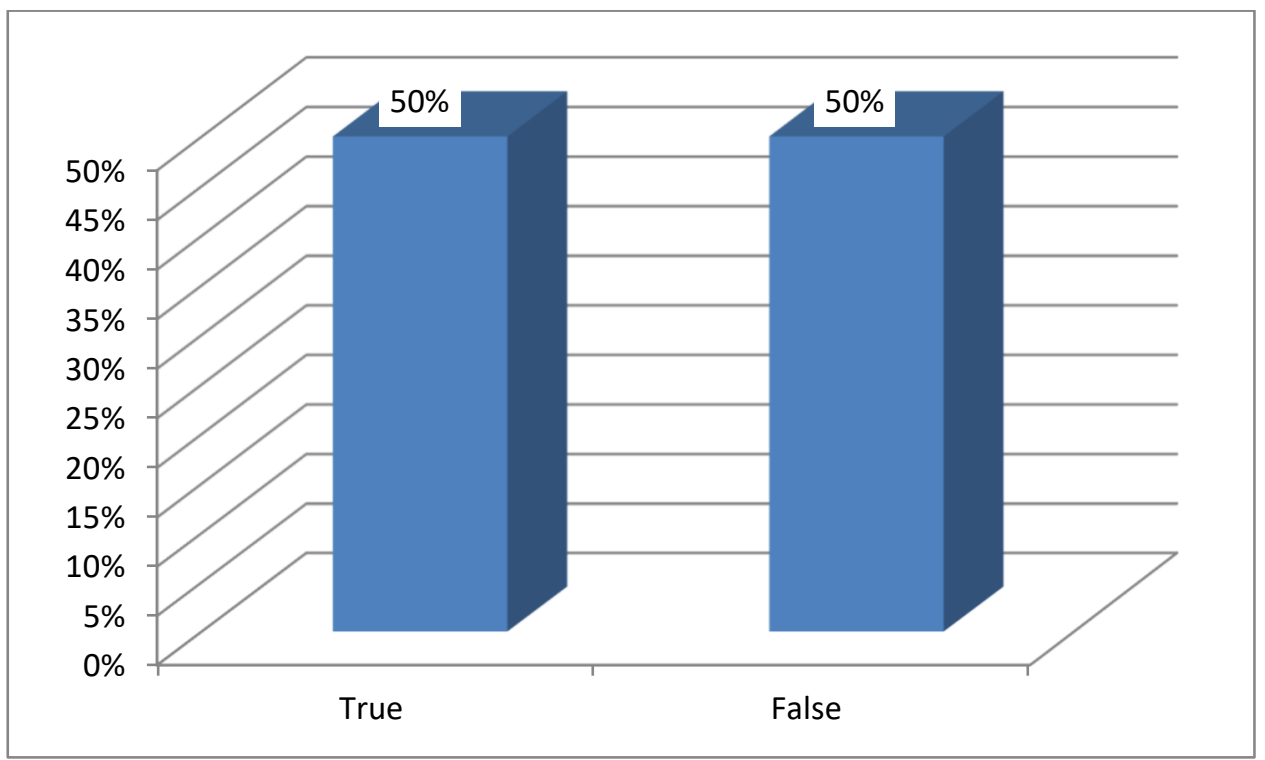

Figure (4.2) The frequency distribution's analysis for item two.

From table (2) and figure (2) we note that the answer of the individuals study is (True and False) by frequency (30) with percent $(50 \%)$ both are equals.

Table (4.3) The frequency distribution's analysis for item three.

\begin{tabular}{|c|c|c|}
\hline Answer & Frequency & percent \\
\hline True & 32 & $53.3 \%$ \\
\hline False & 28 & $46.7 \%$ \\
\hline Total & 60 & $100 \%$ \\
\hline
\end{tabular}

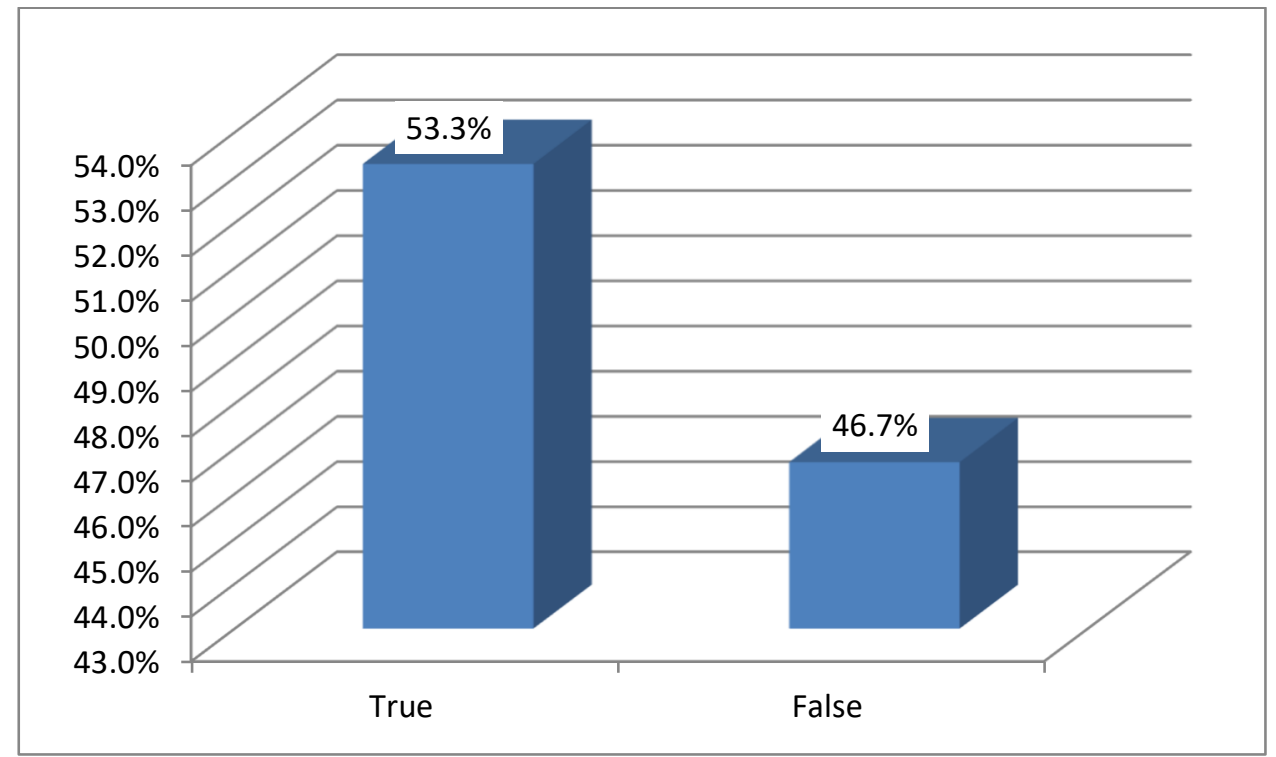

Figure (4.3) The frequency distribution's analysis for item three.

From table (3) and figure (3) we note that the answer of most of the individuals study is (True) by frequency (32) with percent $(53.3 \%)$ while the answer is (False) by frequency (28) with percent $(46.7 \%)$ respectively are low Table (4.4) The frequency distribution's analysis for item four.

\begin{tabular}{|c|c|c|}
\hline Answer & Frequency & percent \\
\hline True & 29 & $48.3 \%$ \\
\hline False & 31 & $51.7 \%$ \\
\hline Total & 60 & $100 \%$ \\
\hline
\end{tabular}




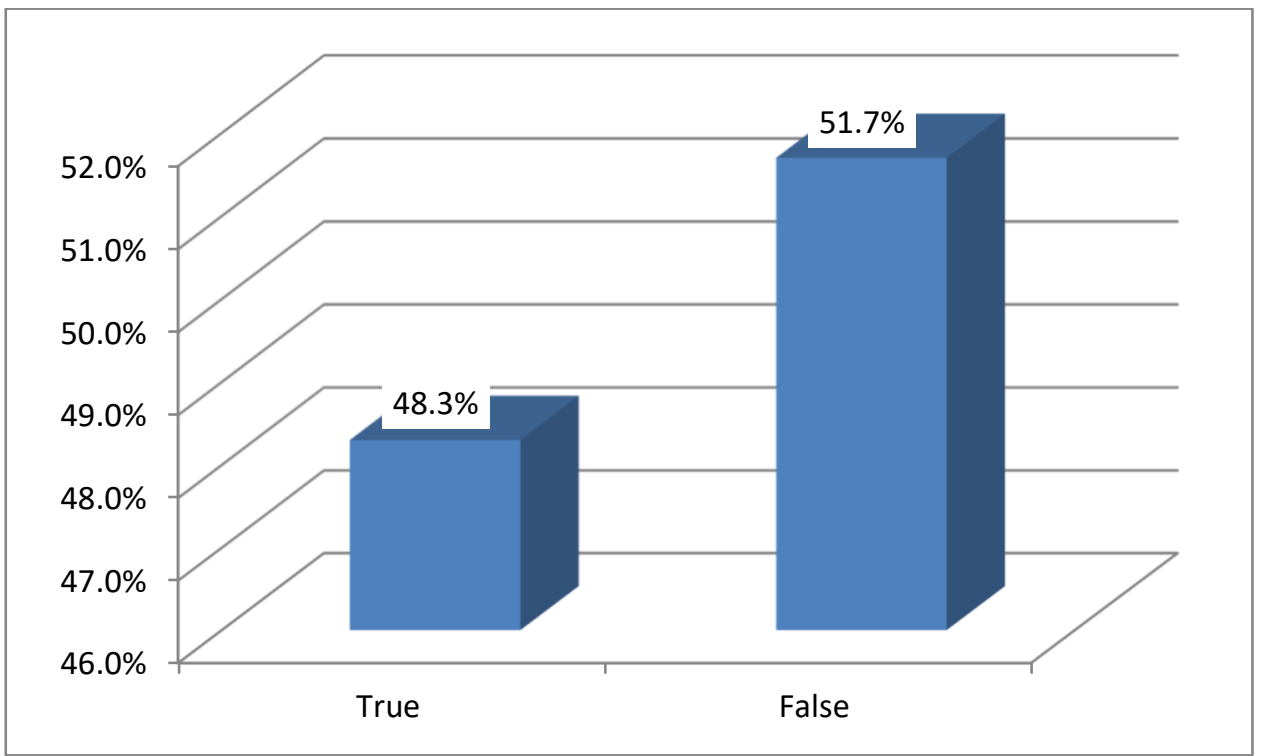

Figure (4.4) The frequency distribution's analysis for item four.

From table (4) and figure (4) we note that the answer of most of the individuals study is (False) by frequency (31) with percent $(51.7 \%)$ while the answer is (True) by frequency (29) with percent (48.3\%) respectively are high ,so the highest percentage is going to positive direction of the statements and most answers of the study sample are agreeable. Therefore this hypothesis is successfully achieved.

Table (4.5) The frequency distribution's analysis for item five.

\begin{tabular}{|c|c|c|}
\hline Answer & Frequency & percent \\
\hline True & 23 & $38.3 \%$ \\
\hline False & 37 & $61.7 \%$ \\
\hline Total & 60 & $100 \%$ \\
\hline
\end{tabular}

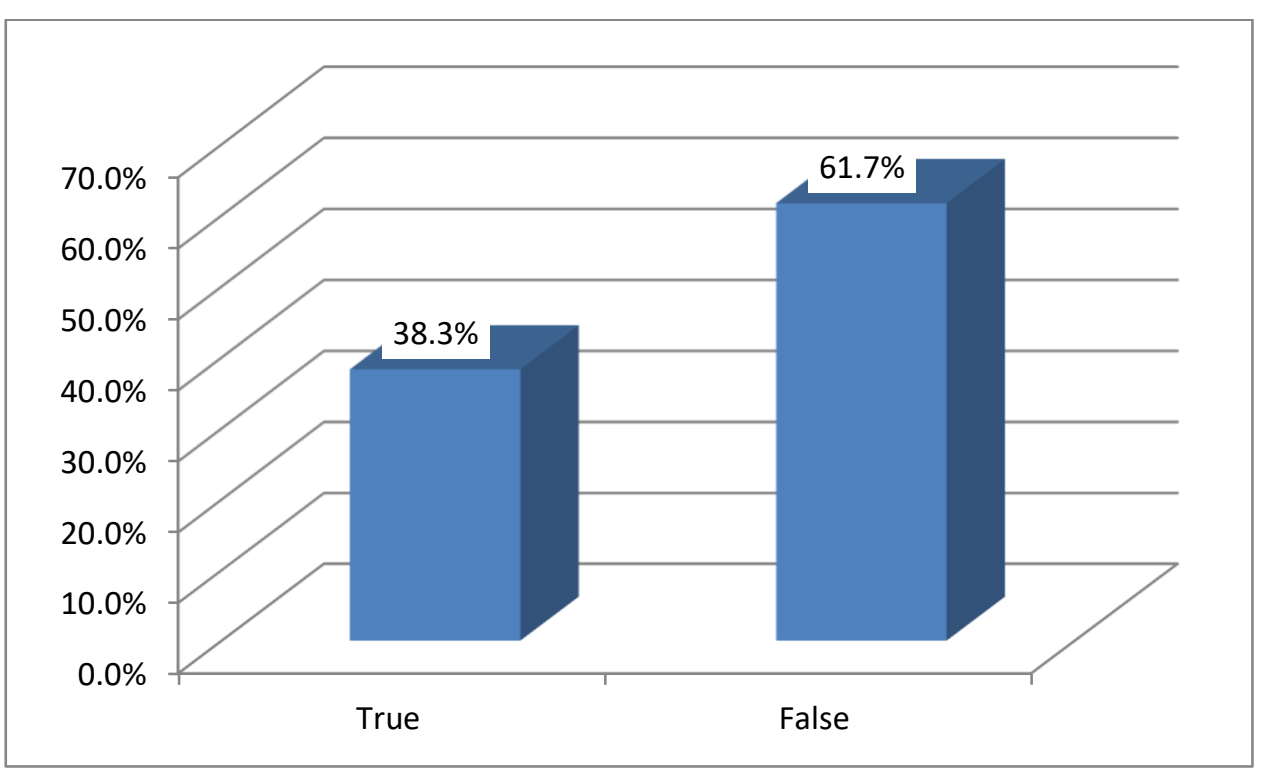

Figure (4.5) The frequency distribution's analysis for item five.

From table (5) and figure (5) we note that the answer of most of the individuals study is (False) by frequency (37) with percent (61.7\%)while the answer is (True) by frequency (23) with percent (38.3\%) respectively are high ,so the highest percentage is going to positive direction of the statements and most answers of the study sample are agreeable. Therefore this hypothesis is successfully achieved. 


\section{2- Part Two}

Table (4.6) The frequency distribution's analysis for item six.

\begin{tabular}{||c|c|c||}
\hline Answer & Frequency & percent \\
\hline \hline True & 25 & $41.7 \%$ \\
\hline False & 35 & $58.3 \%$ \\
\hline \hline Total & 60 & $100 \%$ \\
\hline
\end{tabular}

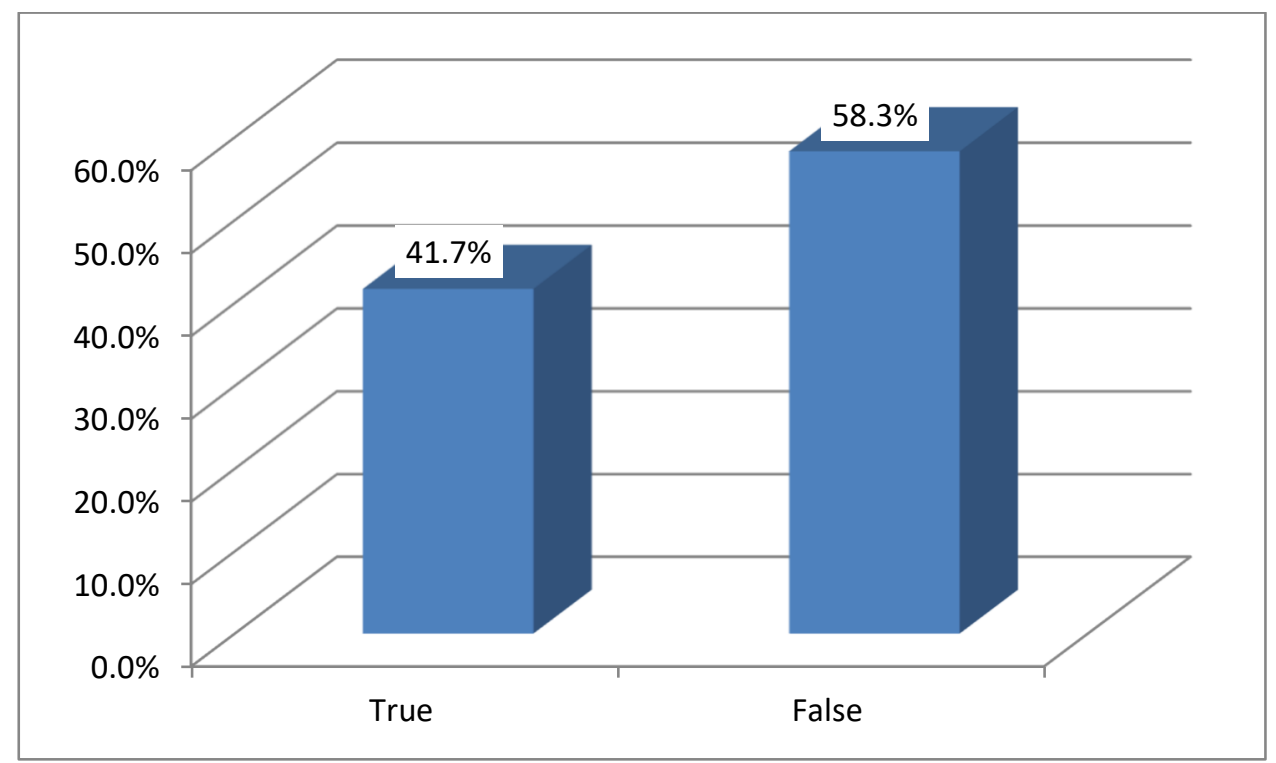

Figure (4.6) The frequency distribution's analysis for item six.

From table (6) and figure (6) we note that the answer of most of the individuals study is (False) by frequency (35) with percent $(58.3 \%$ )while the answer is (True) by frequency (25) with percent (41.7\%) respectively are high ,so the highest percentage is going to positive direction of the statements and most answers of the study sample are agreeable. Therefore this hypothesis is successfully achieved.

Table (4.7) The frequency distribution's analysis for item seven.

\begin{tabular}{|c|c|c|}
\hline Answer & Frequency & percent \\
\hline True & 31 & $51.7 \%$ \\
\hline False & 29 & $48.3 \%$ \\
\hline Total & 60 & $100 \%$ \\
\hline
\end{tabular}

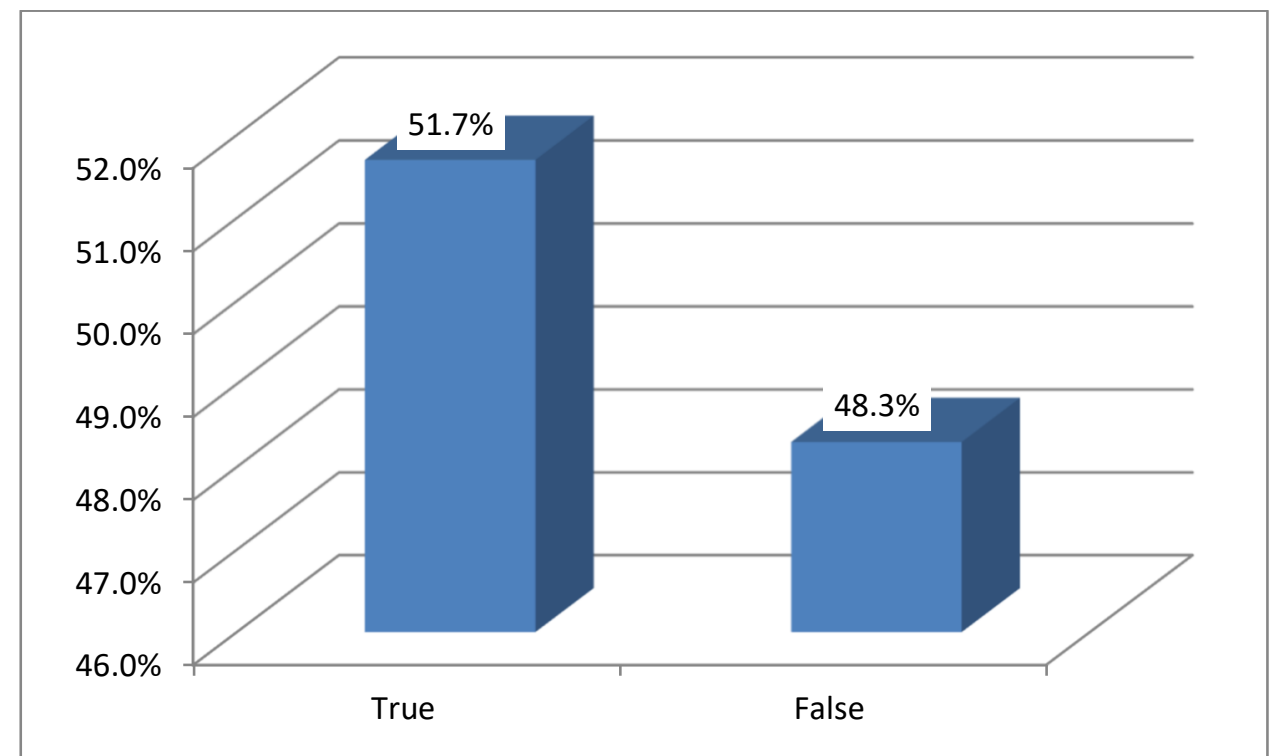

Figure (4.7) The frequency distribution's analysis for item seven.

From table (7) and figure (7) we note that the answer of most of the individuals study is (True) by frequency (31) with percent $(51.7 \%)$ while the answer is (False) by frequency (29) with percent $(48.3 \%)$ respectively are low. 
Table (4.8) The frequency distribution's analysis for item eight.

\begin{tabular}{|c|c|c|}
\hline Answer & Frequency & percent \\
\hline True & 25 & $41.7 \%$ \\
\hline False & 35 & $58.3 \%$ \\
\hline Total & 60 & $100 \%$ \\
\hline
\end{tabular}

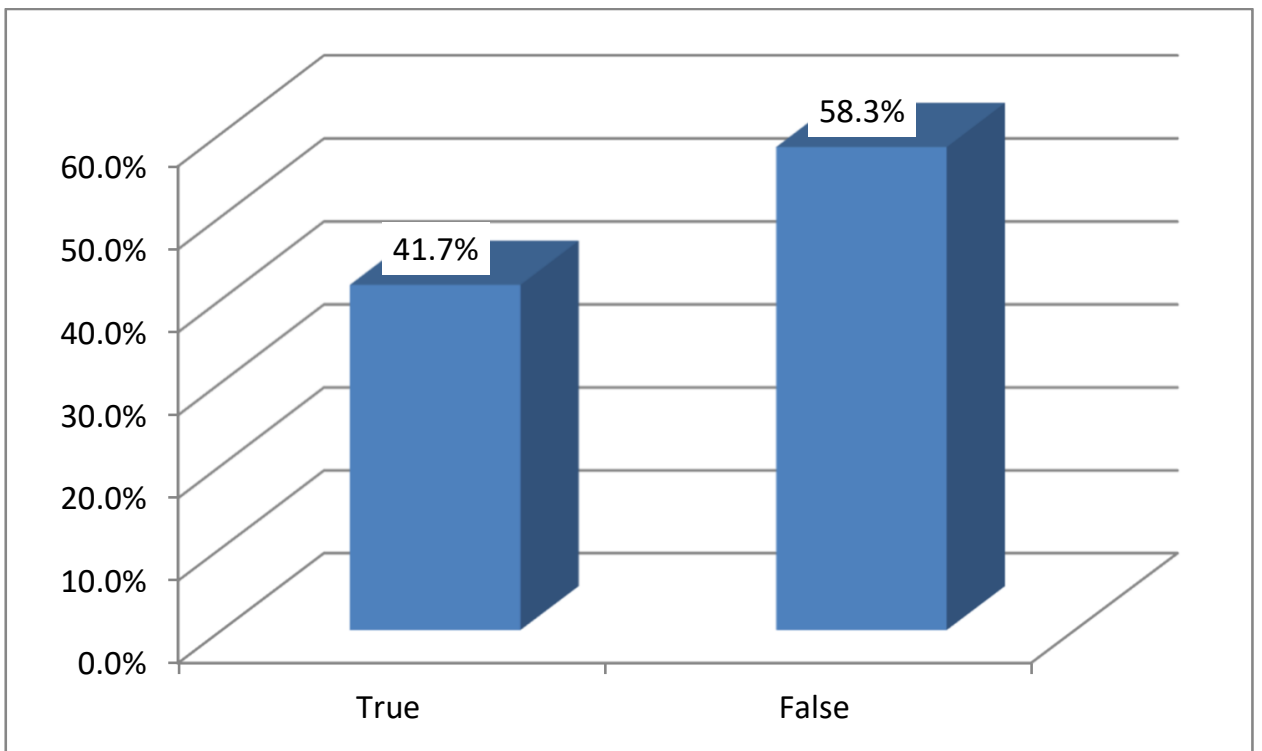

Figure (4.8) :The frequency distribution's analysis for item eight.

From table (8) and figure (8) we note that the answer of most of the individuals study is (False) by frequency (35) with percent (58.3\%)while the answer is (True) by frequency (25) with percent (41.7\%) respectively are high ,so the highest percentage is going to positive direction of the statements and most answers of the study sample are agreeable. Therefore this hypothesis is successfully achieved.

Table (4.9) :The frequency distribution's analysis for item nine.

\begin{tabular}{|c|c|c|}
\hline Answer & Frequency & percent \\
\hline True & 13 & $21.7 \%$ \\
\hline False & 47 & $78.3 \%$ \\
\hline Total & 60 & $100 \%$ \\
\hline
\end{tabular}

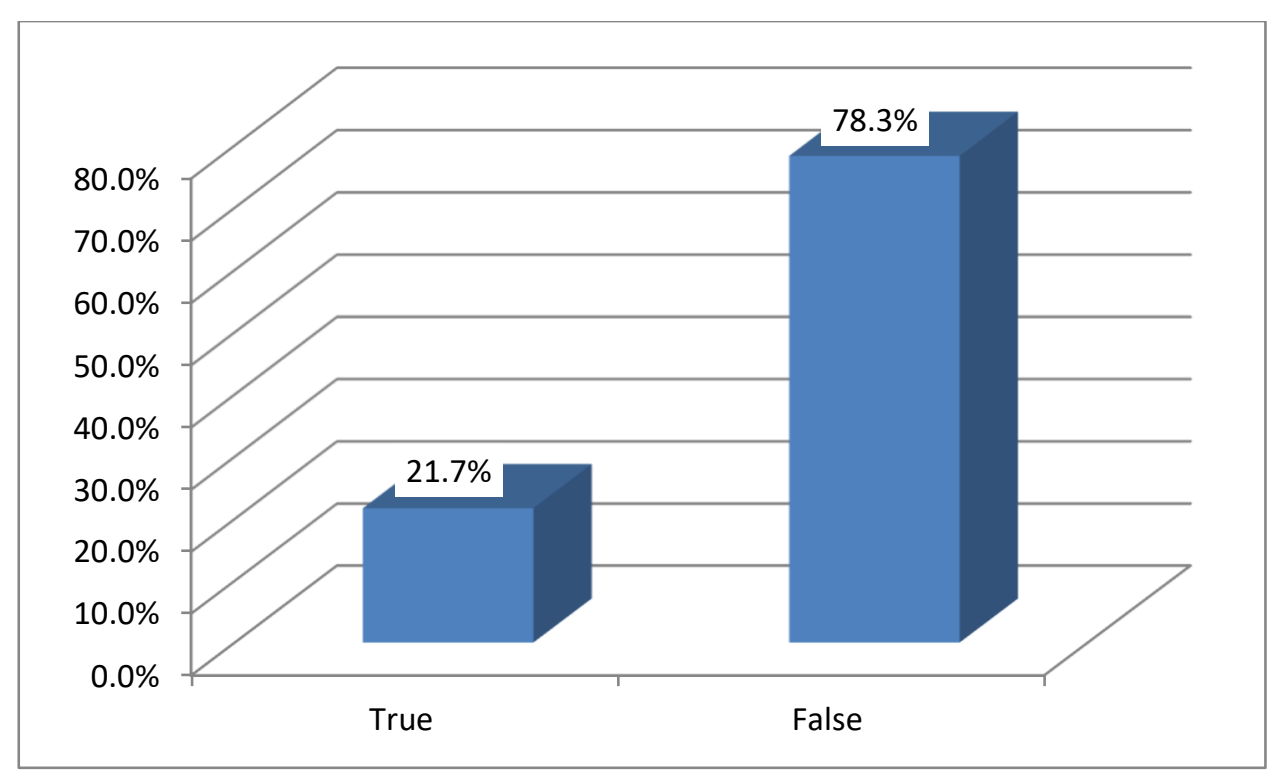

Figure (4.9) :The frequency distribution's analysis for item nine.

From table (9) and figure (9) we note that the answer of most of the individuals study is (False) by frequency (47) with percent (78.3\%)while the answer is (True) by frequency (13) with percent (21.7\%) respectively are high ,so the highest percentage is going to positive direction of the statements and most answers of the study 
sample are agreeable. Therefore this hypothesis is successfully achieved.

Table (4.10) : The frequency distribution's analysis for item ten.

\begin{tabular}{|c|c|c|}
\hline Answer & Frequency & percent \\
\hline True & 23 & $38.3 \%$ \\
\hline False & 37 & $61.7 \%$ \\
\hline Total & 60 & $100 \%$ \\
\hline
\end{tabular}

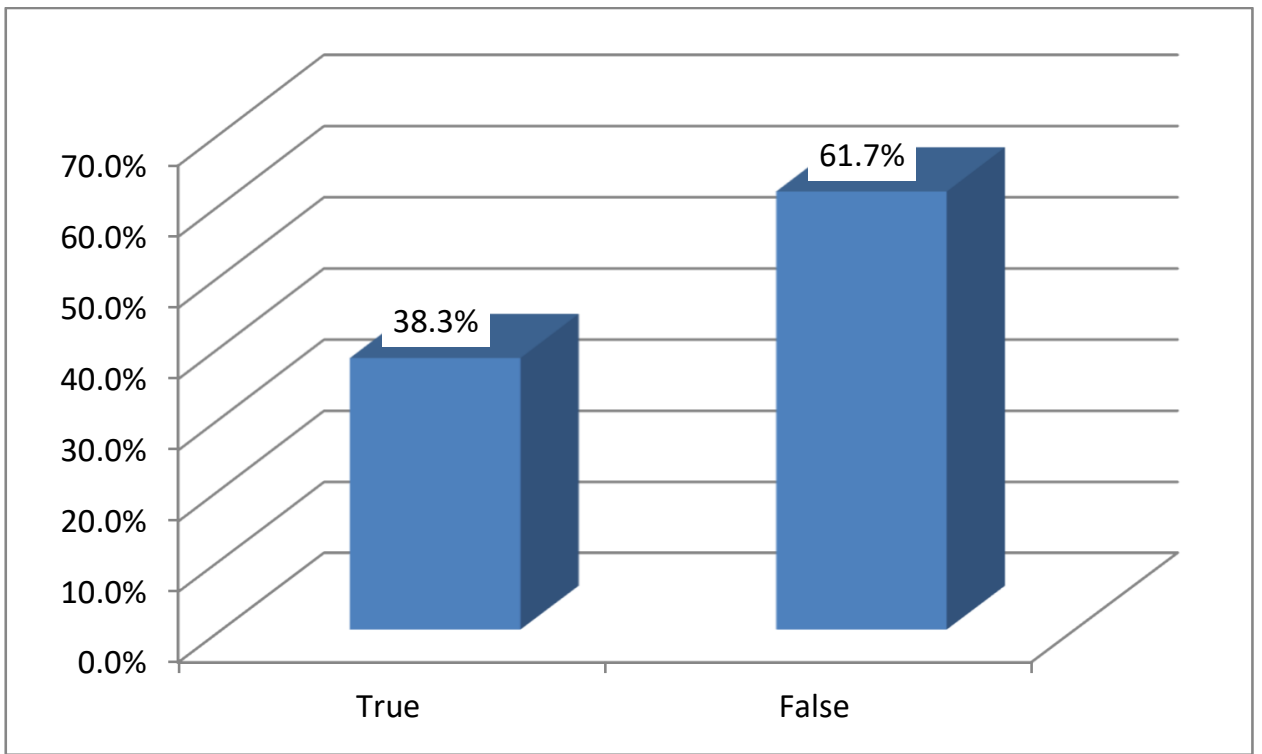

Figure (4.10) :The frequency distribution's analysis for item ten.

From table (10) and figure (10) we note that the answer of most of the individuals study is (False) by frequency (37) with percent $(61.7 \%)$ while the answer is (True) by frequency (23) with percent $(38.3 \%)$ respectively are high ,so the highest percentage is going to positive direction of the statements and most answers of the study sample are agreeable. Therefore this hypothesis is successfully achieved.

3- Part Three

Table (4.11) :The frequency distribution's analysis for item eleven.

\begin{tabular}{|c|c|c|}
\hline Answer & Frequency & percent \\
\hline True & 7 & $11.7 \%$ \\
\hline False & 53 & $88.3 \%$ \\
\hline Total & 60 & $100 \%$ \\
\hline
\end{tabular}

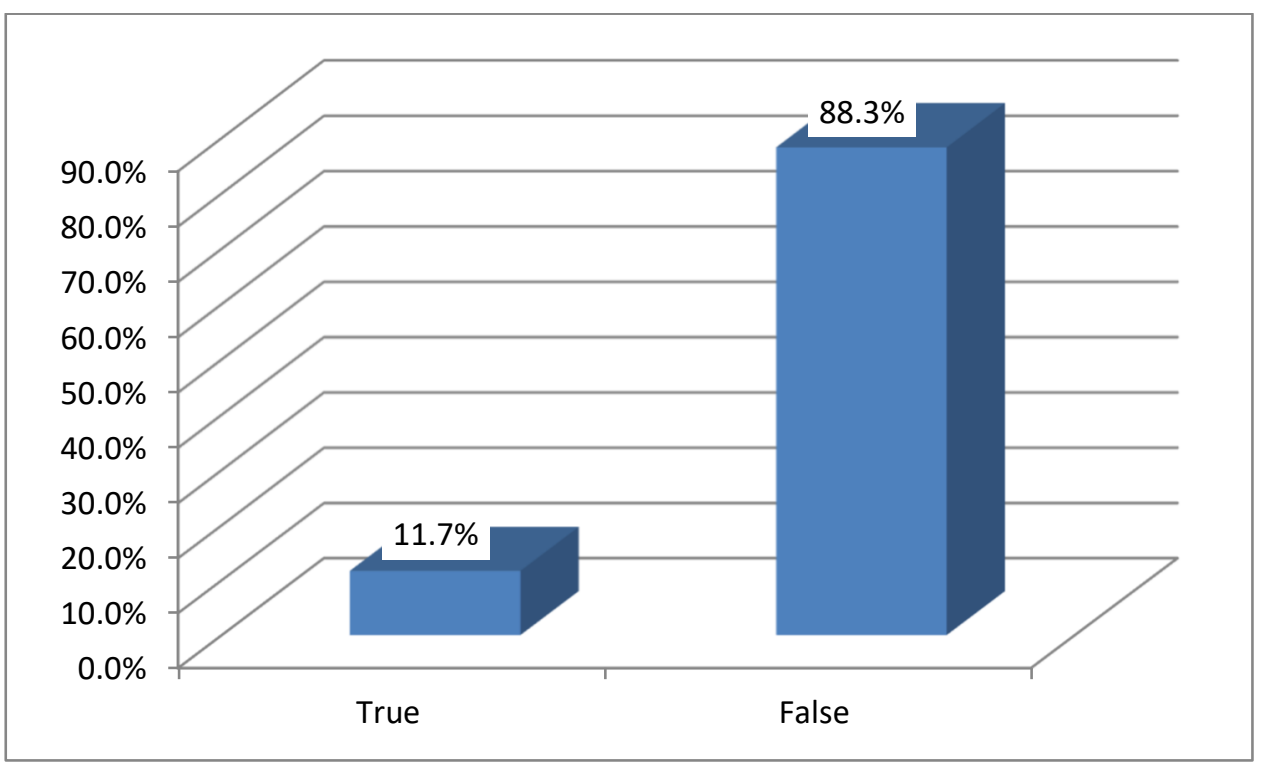

Figure (4.11) :The frequency distribution's analysis for item eleven. 
From table (11) and figure (11) we note that the answer of most of the individuals study is (False) by frequency (53) with percent $(88.3 \%$ )while the answer is (True) by frequency (7) with percent $(11.7 \%)$ respectively are high ,so the highest percentage is going to positive direction of the statements and most answers of the study sample are agreeable. Therefore this hypothesis is successfully achieved.

Table (4.12): The frequency distribution's analysis for item twelve.

\begin{tabular}{|c|c|c|}
\hline Answer & Frequency & percent \\
\hline True & 12 & $20 \%$ \\
\hline False & 48 & $80 \%$ \\
\hline Total & 60 & $100 \%$ \\
\hline
\end{tabular}

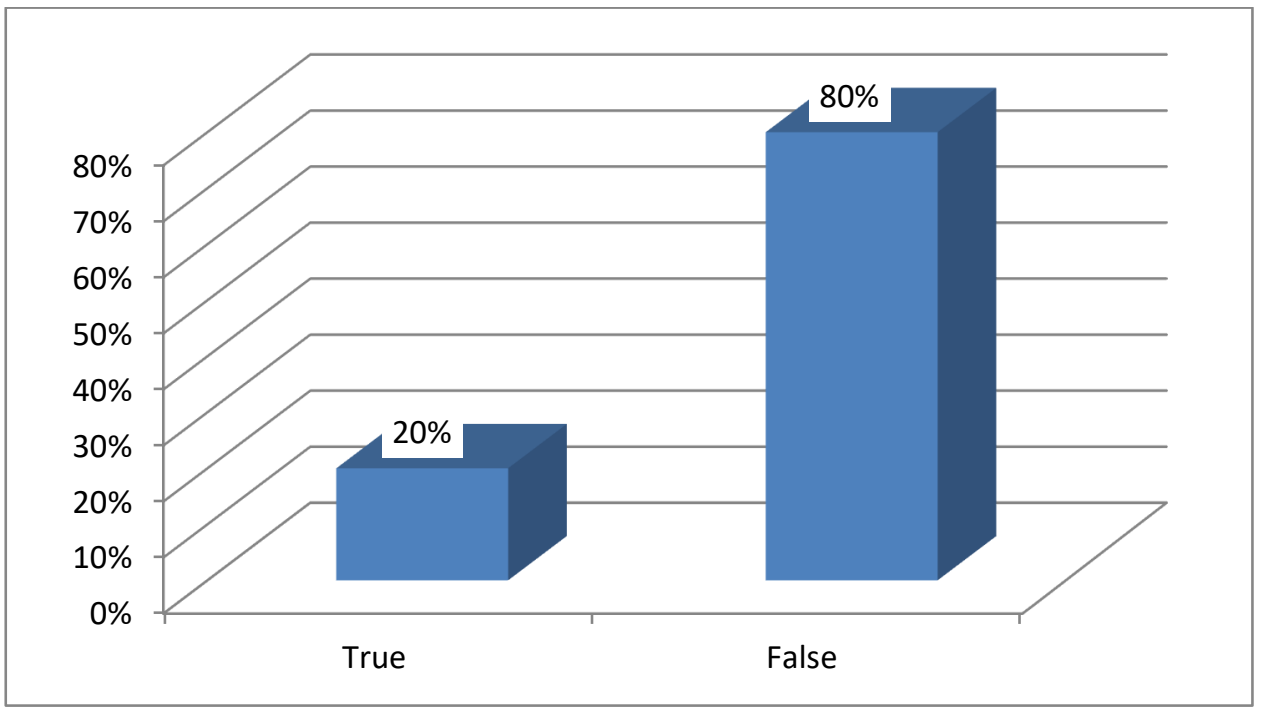

Figure (4.12) The frequency distribution's analysis for item twelve.

From table (12) and figure (12) we note that the answer of most of the individuals study is (False) by frequency (48) with percent (80\%)while the answer is (True) by frequency (12) with percent $(20 \%)$ respectively are high ,so the highest percentage is going to positive direction of the statements and most answers of the study sample are agreeable. Therefore this hypothesis is successfully achieved.

Table (4.13) The frequency distribution's analysis for item on thirteen.

\begin{tabular}{|c|c|c|}
\hline Answer & Frequency & percent \\
\hline True & 4 & $6.7 \%$ \\
\hline False & 56 & $93.3 \%$ \\
\hline Total & 60 & $100 \%$ \\
\hline
\end{tabular}

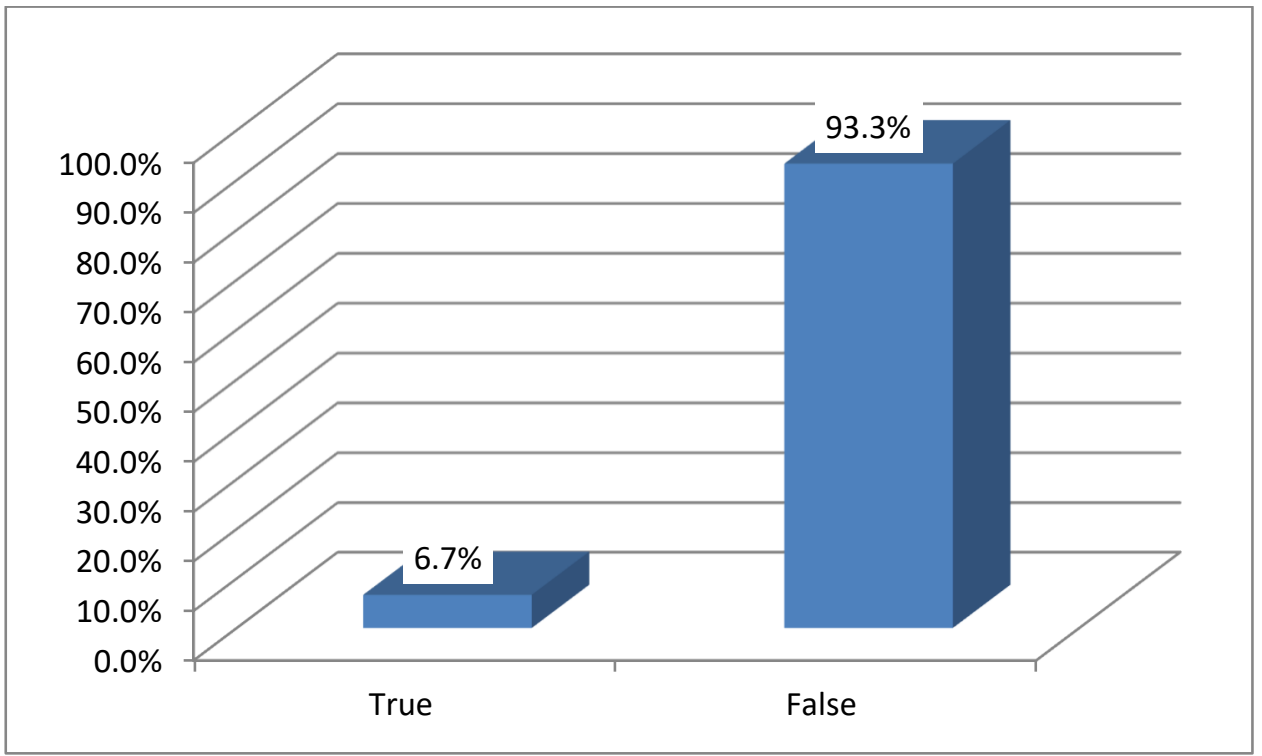

Figure (4.13) The frequency distribution's analysis for item on thirteen. 
From table (13) and figure (13) we note that the answer of most of the individuals study is (False) by frequency (56) with percent (93.3\%)while the answer is (True) by frequency (4) with percent (6.7\%) respectively are high ,so the highest percentage is going to positive direction of the statements and most answers of the study sample are agreeable. Therefore this hypothesis is successfully achieved.

Table (4.14) The frequency distribution's analysis for item fourteen.

\begin{tabular}{|c|c|c|}
\hline Answer & Frequency & percent \\
\hline True & 13 & $21.7 \%$ \\
\hline False & 47 & $78.3 \%$ \\
\hline Total & 60 & $100 \%$ \\
\hline
\end{tabular}

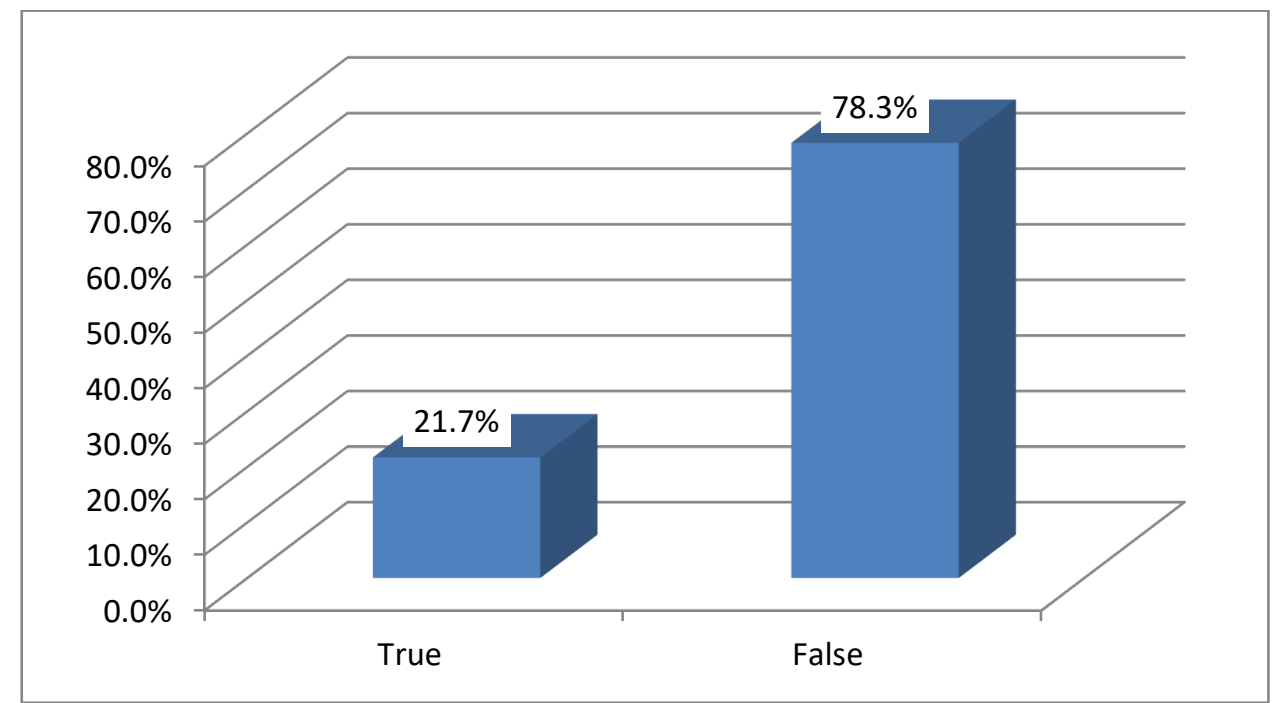

Figure (4.14) The frequency distribution's analysis for item fourteen.

From table (14) and figure (14) we note that the answer of most of the individuals study is (False) by frequency (47) with percent $(78.3 \%$ )while the answer is (True) by frequency (13) with percent $(21.7 \%)$ respectively are high ,so the highest percentage is going to positive direction of the statements and most answers of the study sample are agreeable. Therefore this hypothesis is successfully achieved.

Table (4.15) The frequency distribution's analysis for item fifteen.

\begin{tabular}{|c|c|c|}
\hline Answer & Frequency & percent \\
\hline True & 10 & $16.7 \%$ \\
\hline False & 50 & $83.3 \%$ \\
\hline Total & 60 & $100 \%$ \\
\hline
\end{tabular}

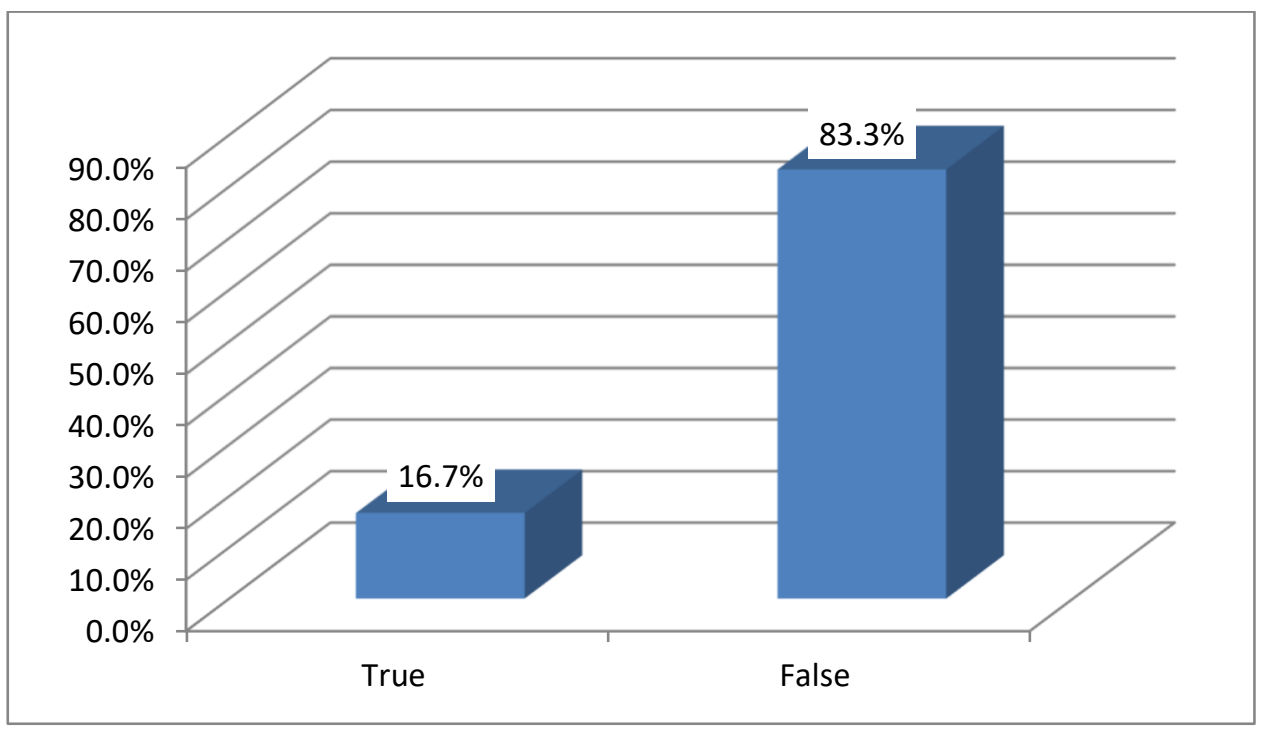

Figure (4.15) The frequency distribution's analysis for item fifteen.

From table (15) and figure (15) we note that the answer of most of the individuals study is (False) by frequency 
(50) with percent $(83.3 \%)$ while the answer is (True) by frequency (10) with percent $(16.7 \%)$ respectively are high ,so the highest percentage is going to positive direction of the statements and most answers of the study sample are agreeable. Therefore this hypothesis is successfully achieved.

\section{4- Part Four}

Table (4.16) The frequency distribution's analysis for item sixteen.

\begin{tabular}{|c|c|c|}
\hline Answer & Frequency & percent \\
\hline True & 22 & $36.7 \%$ \\
\hline False & 38 & $63.3 \%$ \\
\hline Total & 60 & $100 \%$ \\
\hline
\end{tabular}

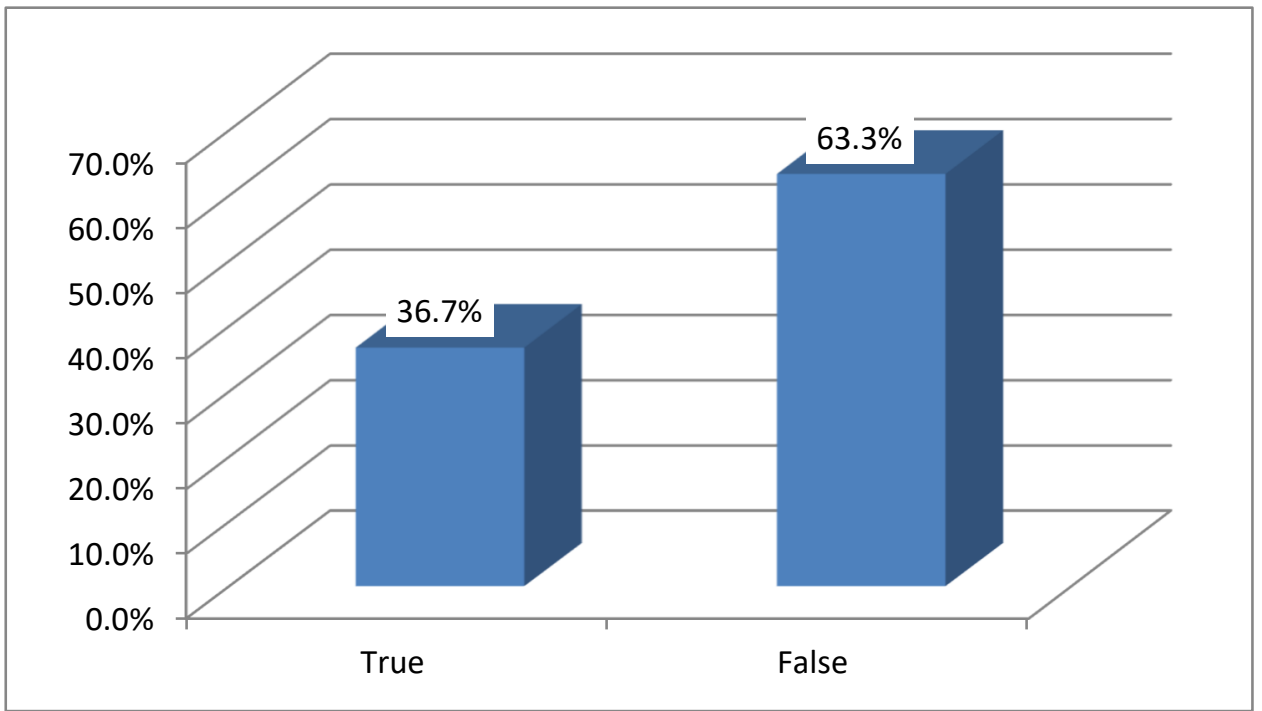

Figure (4.16) The frequency distribution's analysis for item sixteen.

From table (16) and figure (16) we note that the answer of most of the individuals study is (False) by frequency (38) with percent $(63.3 \%$ )while the answer is (True) by frequency (22) with percent (36.7\%) respectively are high ,so the highest percentage is going to positive direction of the statements and most answers of the study sample are agreeable. Therefore this hypothesis is successfully achieved.

Table (4.17) The frequency distribution's analysis for item seventeen.

\begin{tabular}{|c|c|c|}
\hline Answer & Frequency & percent \\
\hline True & 24 & $40 \%$ \\
\hline False & 36 & $60 \%$ \\
\hline Total & 60 & $100 \%$ \\
\hline
\end{tabular}

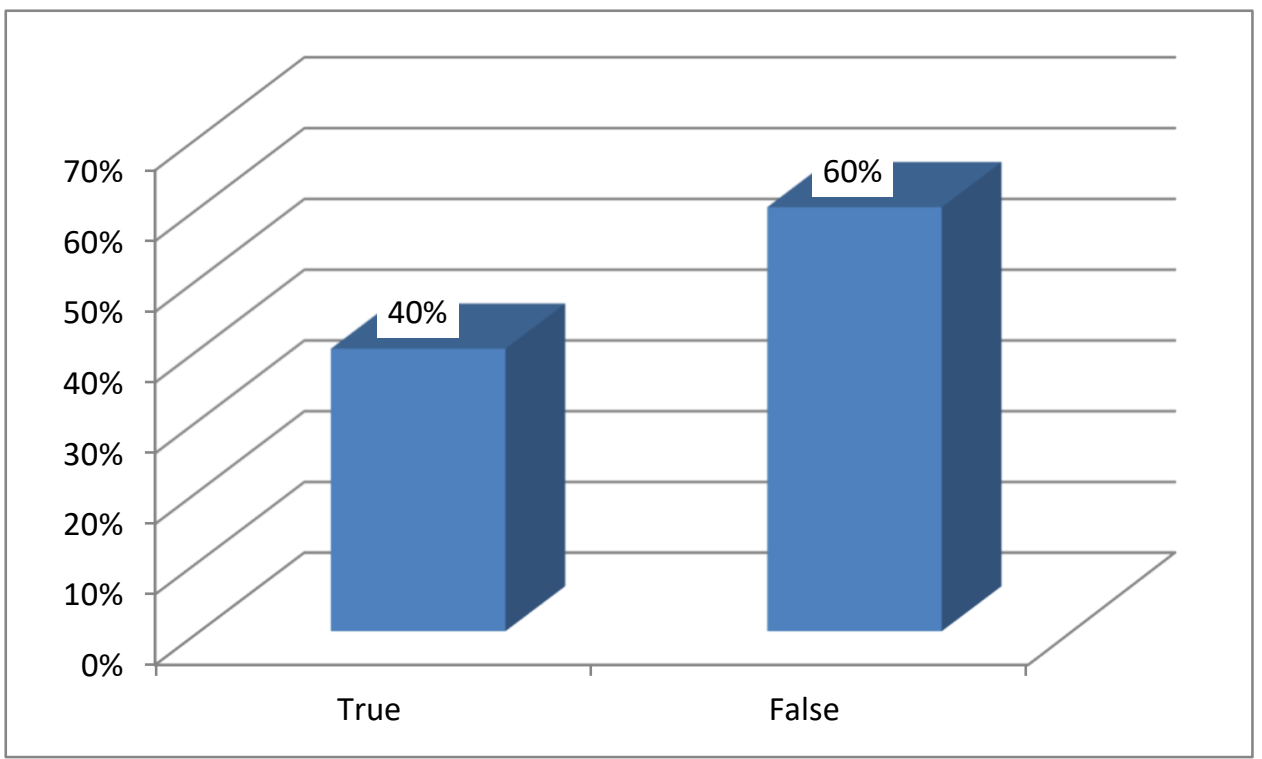

Figure (4.17) The frequency distribution's analysis for item seventeen. 
From table (17) and figure (17) we note that the answer of most of the individuals study is (False) by frequency (36) with percent $(60 \%)$ while the answer is (True) by frequency (24) with percent (40\%) respectively are high ,so the highest percentage is going to positive direction of the statements and most answers of the study sample are agreeable. Therefore this hypothesis is successfully achieved.

Table (4.18) The frequency distribution's analysis for item eighteen.

\begin{tabular}{|c|c|c|}
\hline Answer & Frequency & percent \\
\hline True & 6 & $10 \%$ \\
\hline False & 54 & $90 \%$ \\
\hline Total & 60 & $100 \%$ \\
\hline
\end{tabular}

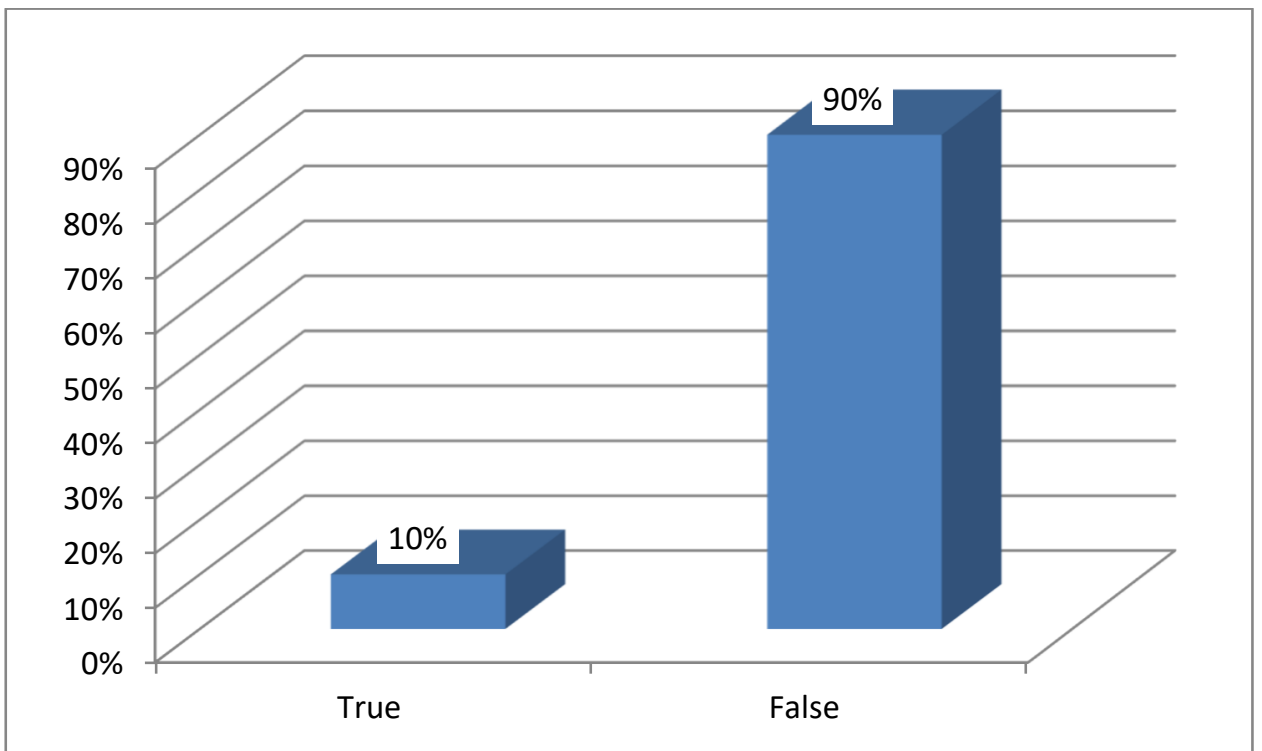

Figure (4.18) The frequency distribution's analysis for item eighteen.

From table (18) and figure (18) we note that the answer of most of the individuals study is (False) by frequency (54) with percent (90\%)while the answer is (True) by frequency (6) with percent (10\%) respectively are high ,so the highest percentage is going to positive direction of the statements and most answers of the study sample are agreeable. Therefore this hypothesis is successfully achieved.

Table (4.19) The frequency distribution's analysis for item nineteen.

\begin{tabular}{|c|c|c|}
\hline Answer & Frequency & percent \\
\hline True & 7 & $11.7 \%$ \\
\hline False & 53 & $88.3 \%$ \\
\hline Total & 60 & $100 \%$ \\
\hline
\end{tabular}

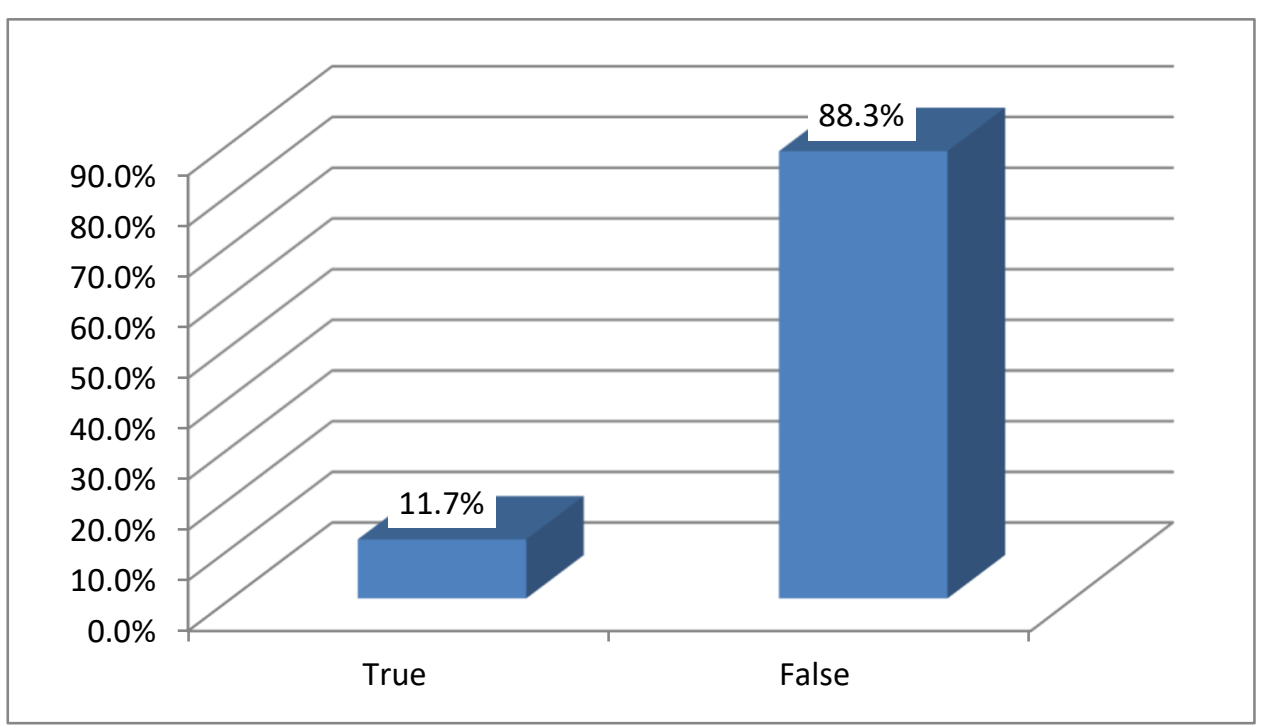

Figure (4.19) the frequency distribution's analysis for item nineteen. 
From table (19) and figure (19) we note that the answer of most of the individuals study is (False) by frequency (53) with percent $(88.3 \%)$ while the answer is (True) by frequency (7) with percent $(11.7 \%)$ respectively are high ,so the highest percentage is going to positive direction of the statements and most answers of the study sample are agreeable. Therefore this hypothesis is successfully achieved.

Table (4.20) the frequency distribution's analysis for item twenty.

\begin{tabular}{|c|c|c|}
\hline Answer & Frequency & percent \\
\hline True & 19 & $31.7 \%$ \\
\hline False & 41 & $68.3 \%$ \\
\hline Total & 60 & $100 \%$ \\
\hline
\end{tabular}

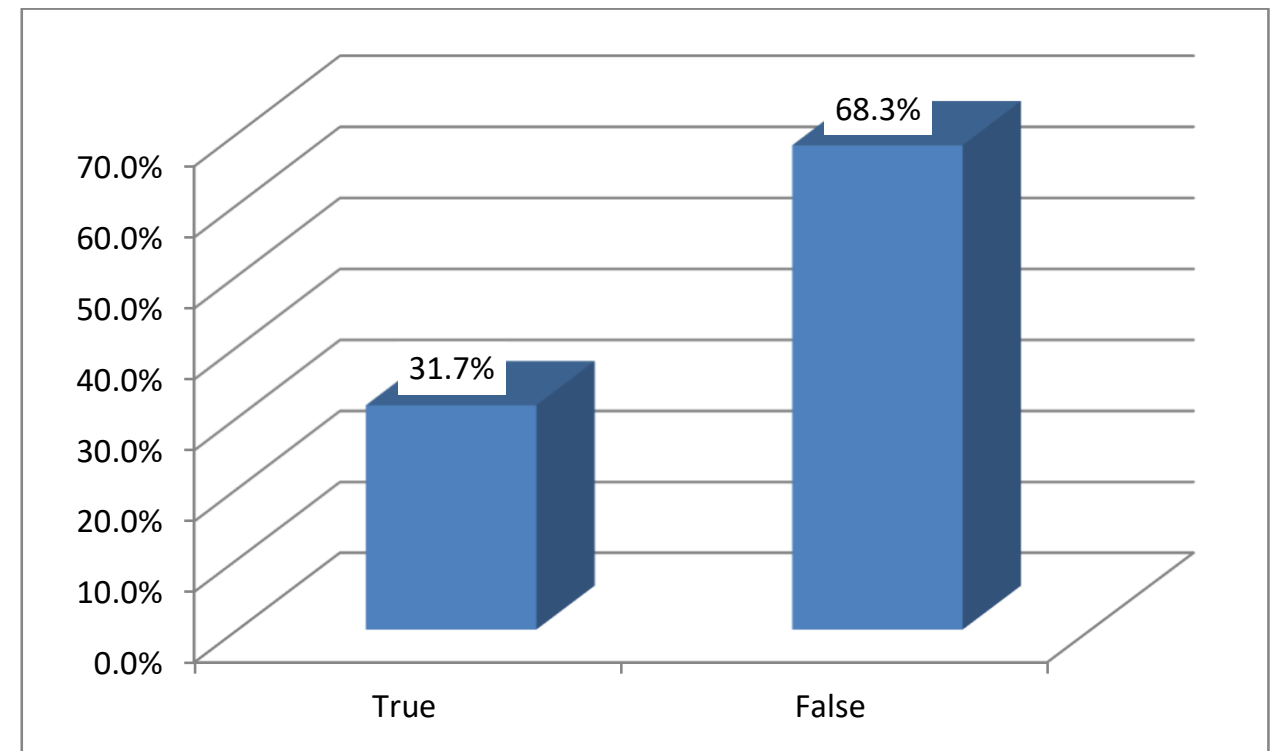

Figure (4.20) The frequency distribution's analysis for item twenty.

From table (20) and figure (20) we note that the answer of most of the individuals study is (False) by frequency (41) with percent $(68.3 \%$ )while the answer is (True) by frequency (19) with percent $(31.7 \%)$ respectively are high ,so the highest percentage is going to positive direction of the statements and most answers of the study sample are agreeable. Therefore this hypothesis is successfully achieved.

\section{The Finding of the Study}

1- Students of the common first year at Majmaah University have general background about the present simple tense.

2-Students do not have a sufficient ability to form the verbs correctly in the present simple tense.

3- Students are very weak in forming negative and interrogative sentences in the present simple tense.

\subsection{Recommendations}

With the reference to the finding of the study, the researcher recommends the following:

1 - The present simple tense should paid agree attention when it is taught.

2- The present simple tense should be taught in the beginning secondary school effectively.

3- Students should do many classroom activities and exercises about the simple present tense.

4- The teachers should use motivations methods to enhance the students' level in the present simple tense.

\subsection{Suggestions for Further Studies}

The researcher suggests the following further areas for other researchers:

1- Investigate the problems which encounter secondary school students in using inflectional morphemes (s, es, ies ) of the present simple tense.

2- Comparative studies could be conducted to find similarities and dissimilarities between the present simple tense and other tenses.

3- Investigating the problems that encounter secondary school students in using the present simple tense when they write a descriptive paragraph.

\section{References}

Arai, T., Aiyama, Y., Sugi, M. \& Ota, J. (2001), "Holonic Assembly System with Plug and Produce", Computers 
in Industry 46, Elsevier, 289-299.

Bell, G.A., Cooper, M.A., Kennedy, M. \& Warwick, J. (2000), “The Development of the Holon Planning and Costing Framework for Higher Education Management”, Technical Report, SBU-CISM-11-00, South Bank University, 103 Borough Road, London, SE1 0AA.

Bongaerts, L. (1998), "Integration of Scheduling and Control in Holonic Manufacturing Systems", PhD Thesis, PMA Division, K.U.Leuven.

Deen, S.M. (1993), “Cooperation Issues in Holonic Manufacturing Systems”, Proceedings of DIISM'93 Conference, 410-412.

Techawiboonwong, A., Yenradeea, P. \& Das, S. (2006). A Master Scheduling Model with Skilled and Unskilled Temporary Workers", Production Economics 103, Elsevier, 798-809.

Valckenaers, P., Van Brussel, H., Bongaerts, L. \& Wyns, J. (1997), “Holonic Manufacturing Systems”, Integrated Computer Aided Engineering 4(3), 191-201.

Van Brussel, H., Wyns, J., Valckenaers, P., Bongaerts, L. \& Peters, P. (1998), "Reference Architecture for Holonic Manufacturing Systems: PROSA”, Computers in Industry 37(3), 255-274.

Abdul Raheem, M. ( 1999 ) English Grammar Errors among the Students of English department at the Colleges of Education in Gazza Governorates. Unpublished M.A Thesis Islamic University - Gazza, Palestinc.

Azzar (1981:20) Alabama Journal; Location: Montgomery, Alabama; Issue Date: Friday, July 3, 1981; Page: 20.

Brown (1980, p. 264). Principles of Language and Teaching. New Jersey: Prentice Hall, inc.

Brown (1980: 163). Principles of language learning and teaching. London: Prentice Hall International.

Cook and Suter, (1983:49). The scope of Grammar. Oxford: University press.

Corder (1981: 260) Error analysis and inter language. London; New York : Oxford University Press,

Corder, (1967), cited in Ellis, (1994) The significance of learner's errors. IRAL-International Review of Applied Linguistics in Language Teaching, 5(1-4), 161-170.

Corder, S. P. (1981). Error Analysis and Inter language. Oxford. Oxford University Press.

ELkhateeb, (2003) analyzed the common English verb tense of secondary school students in Gaza city.

Ellis, (1997; 17). Second Language Acquisition. Oxford. Oxford University Press.

Frank, (1972:66) Moodern English New Jersey: Prentice Hall inc

Gass and Slinker, (1994) S. Gass, L. SlinkerSecond Language Acquisition: an Introductory Course.

Lightbown and Spada, (2006). Foreign Language Study; Oxford University Press.

Lightbown, P. M., \& Spada, N. (2006). How languages are learned. Oxford: Oxford University Press.

Mahmoud, A (2005). Collocation errors made by Arab learners of English. Asia EFL Journal. Retrieved 2015, from the World Wide Web: Http://www. Asian- efl - Journal. Com /.

Muneera, M. \& Shmeem. R ( 2013 ). Error Analysis of present simple tense in the interlanguage of adult Arab English language learners. English language teaching, 6, 2.

Norma gold man and etal - (1983) English Grammar for Students of Latin which she co-authored with Ladislas Szymanski.

Norris and Ortega (2003, p. 717). Defining and measuring SLA. In Doughty, C. J., \& Long, M. C. (Eds), the Handbook of Second Language Acquisition. Malden, MA: Blackwell Publishing.

Patricia Wilox - (1996) Developing Writing: Writing Skills Practice Book for Beginning/intermediate Students of English as a Foreign Language, Publisher English Language Programs Division.

Sheryl Holt, (1997) Holt Handbook Minneapolis: Runestone Press.

Sheryl Holt, (1997) the most common errors in English as the Second Language Writing: University of Minnesota.

Thornbury, S. (2002) How to teach grammar. Pearson Education: Limited, Malaysia.

https://www.ef.com/wwen/english-resources/english-grammar/simple-present-tense/

https://www.englishpage.com/verbpage/simplepresent.html 